\title{
Iridium-Bismuth Cluster Complexes yield Bimetallic Nano- Catalysts for the Direct Oxidation of 3-Picoline to Niacin
}

\author{
Richard D. Adams, ${ }^{\zeta}$ Mingwei Chen, ${ }^{\zeta}$ Gaya Elpitiya, ${ }^{\zeta}$ Matthew E. Potter ${ }^{\S}$ and Robert Raja*§ \\ 'Department of Chemistry and Biochemistry, University of South Carolina, Columbia, SC, 29208. \\ ${ }^{\S}$ School of Chemistry, University of Southampton, Highfield, Southampton SO17 1BJ, U.K.
}

KEYWORDS: Nanocluster, selective oxidation, iridium-bismuth, niacin, catalytic synergy, anchored nanoparticles, $C$ - $H$ activation

\begin{abstract}
The reaction of $\operatorname{Ir}_{3}(\mathrm{CO})_{9}\left(\mu_{3}-\mathrm{Bi}\right), \mathbf{1}$ with $\mathrm{BiPh}_{3}$ has yielded a iridium-bismuth cluster complex $\operatorname{Ir}_{5}(\mathrm{CO})_{10}\left(\mu_{3}-\mathrm{Bi}\right)_{2}\left(\mu_{4^{-}}\right.$ $\mathrm{Bi}), \mathbf{2}$. The first examples of bimetallic iridium-bismuth nanoparticles have been subsequently synthesized from $\mathbf{1}$ and $\mathbf{2}$ and these have been securely anchored on to the inner walls of mesoporous silica. These isolated, bimetallic iridium-bismuth nanoparticles display a superior catalytic performance, when compared to their analogous monometallic counterparts and equivalent physical mixtures, in the $\mathrm{C}-\mathrm{H}$ activation of 3-picoline to yield niacin.
\end{abstract}

Probing the origins of the catalytic synergy between multimetallic active centers in porous solids, wherein a Platinum Group Metal (PGM) such as Ru, Pt or Rh, is alloyed with suitable oxophiles such as $\mathrm{Sn}, \mathrm{Bi}$ or Mo facilitates the rational design of well-isolated, single-site nanoparticle catalysts, that exhibit enhanced stability and improved catalytic performance. ${ }^{1,2}$ Tailoring suitable oxophiles in combination with multimetallic clusters has afforded intrinsic compositional control at the nanoscale, with the added advantage of controlling the morphology, size and shape of the ensuing nakedmetal nanoparticles. ${ }^{3-5}$ Such a design approach could be integrated with bespoke support modifications (e.g. tuning the hydrophobicity) to yield both functional and structural synergies facilitating structure-property relationships to be established. ${ }^{6}$ The precise controlled synthesis of catalytically-active metal nanoparticles has been of great interest in recent years, ${ }^{7,8}$ with the ever-expanding target of creating discrete single-sites. With a view to achieving this goal, a number of elegant strategies using inorganic porous supports, ${ }^{9-11}$ polymer-stabilized matrices $^{12}$ and framework extrusion processes $^{13}$ have been developed. Despite the intrinsic merits of these approaches, ${ }^{9-13}$ the desire to modulate catalytic activity and selectivity at the nanoscale, through the adroit choice of appropriate metal combinations and their concomitant oxophilic analogues, for generating uniform, discrete, well-defined, multifunctional single-sites, remains a challenging prospect. ${ }^{14}$

Bismuth on oxide supports has been shown to catalyze the oxidation of certain hydrocarbons heterogeneously. ${ }^{15}$ Bismuth molybdate is well known for its ability to catalyze the ammoxidation of propene. ${ }^{16} \mathrm{We}$ have recently shown that a bimetallic rhenium-bismuth catalyst, derived from a rhenium-bismuth complex $\operatorname{Re}_{2}(\mathrm{CO})_{8}\left(\mu-\mathrm{BiPh}_{2}\right)_{2}$, can selectively convert 3picoline to 3-nicotinonitrile. ${ }^{2}$ The ability of the oxophile (bismuth in this case) to interact favorably with the mesoporous silica support, through the covalent-bond formation between the oxophilic metal and pendant silanol groups, renders this nanoparticle catalyst amenable for oxidation reactions. ${ }^{3,5}$ Furthermore, the capping of the $\mathrm{CO}$ ligands on the nano-cluster precursor, improve the degree of site-isolation, leading to the creation of the catalytically active nanoparticle catalyst. It has been previously demonstrated ${ }^{1-5}$ that the subsequent removal of the CO ligands, generates uniform $(<5 \mathrm{~nm})$, well-defined, anchored bimetallic nanoparticles, where the bismuth plays a pivotal role in securing the nanoclusters to the support and ensuring its compositional integrity. ${ }^{3-5}$ Furthermore, it has also been demonstrated that bismuth plays a key role in enhancing the catalytic efficiency in a range of selective oxidation reactions. ${ }^{17-19}$ Most notable is the combination of bismuth with precious metals to form $\mathrm{Pd}-\mathrm{Bi}^{17}$ and $\mathrm{Pt}-\mathrm{Bi}^{18}$ species. While the exact role of bismuth in such catalysts is not conclusive, it has been suggested that the production of 2,5-furandicarboxylic acid (FDCA) from hydroxymethylfurfural (HMF) was appreciably increased owing to the favourable interaction between $\mathrm{Bi}$ atoms and $\pi$-electrons in the furan ring. ${ }^{18}$ There are also other plausibilities attributing the promoter ability of Bi to its oxophilicity, ${ }^{6,17}$ which enhances the ability of bismuth to activate molecular oxygen thereby facilitating $\alpha-\mathrm{H}$ abstraction. ${ }^{19}$ These unique properties of the bismuth prompted us to devise other bimetallic catalysts and we report herein, for the first time, the design of two novel iridium-bismuth bimetallic nanoclusters that are derived from new Ir-Bi complexes. Preliminary catalytic studies, outlining the performance of these new iridium-bismuth nanoparticle catalysts for the direct oxidation of 3-picoline to niacin are reported, offering a subtle contrast to the previously reported ${ }^{2}$ ammoxidation route to nicotinonitrile (precursor to niacin). Until recently, the only example of an iridium-bismuth complex was the compound $\mathrm{Ir}_{3}(\mathrm{CO})_{9}\left(\mu_{3}-\mathrm{Bi}\right), 1$ that was reported by $\mathrm{Schmid} .{ }^{20}$ We have recently prepared a number of iridium-bismuth complexes containing germanium and tin ligands from complex 1 by reactions with $\mathrm{HGePh}_{3}$ and $\mathrm{HSnPh}_{3}{ }^{21}$ We have now found that 1 reacts with $\mathrm{BiPh}_{3}$ to yield the new higher nuclearity complex $\operatorname{Ir}_{5}(\mathrm{CO})_{10}\left(\mu_{3}-\mathrm{Bi}\right)_{2}\left(\mu_{4}-\mathrm{Bi}\right), 2$ in high yield $(91 \%)$, see Scheme 1. Compound 2 was characterized crystallographically by singlecrystal X-ray diffraction and an ORTEP diagram of its molecular structure is shown in Figure 2. ${ }^{22}$ The molecule lies on a 
reflection plane in the solid state. Compound $\mathbf{2}$ contains five iridium atoms arranged in the form of a square pyramid.

Scheme 1. A schematic of the transformation of 1 to 2 by reaction with $\mathrm{BiPh}_{3}$. $\mathrm{CO}$ ligands are shown only as lines.

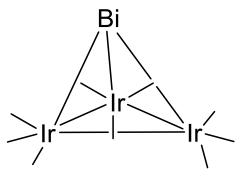

1

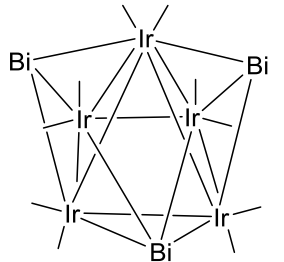

2
Complex 2 contains three bridging bismuth atoms: atom $\mathrm{Bi}(1)$ is a quadruple bridge that spans the base of the $\mathrm{Ir}_{5}$ square pyramid; the other two, $\operatorname{Bi}(2)$ and $\operatorname{Bi}(3)$, are triply-bridging ligands that bridge oppositely positioned triangular faces of the square pyramid. The $\mathrm{Ir}-\mathrm{Ir}$ and $\mathrm{Ir}-\mathrm{Bi}$ bond distances, $\operatorname{Ir}(1)-\operatorname{Ir}(2)=2.7824(7) \AA, \operatorname{Ir}(1)-\operatorname{Ir}(3)=2.8226(7) \AA, \operatorname{Ir}(2)-$ $\operatorname{Ir}(3)=2.7903(7) \AA, \operatorname{Ir}(2)-\operatorname{Ir}\left(2^{\prime}\right)=2.8255(9) \AA, \operatorname{Ir}(3)-\operatorname{Ir}\left(3^{\prime}\right)$ $=2.7796(9) \AA, \operatorname{Ir}(1)-\operatorname{Bi}(3)=2.8322(9), \operatorname{Ir}(1)-\operatorname{Bi}(2)=$ 2.7623(9), $\operatorname{Ir}(2)-\mathrm{Bi}(3)=2.6868(7), \operatorname{Ir}(2)-\mathrm{Bi}(1)=2.8004(7)$, $\operatorname{Ir}(3)-\operatorname{Bi}(2)=2.7002(7), \operatorname{Ir}(3)-\operatorname{Bi}(1)=2.8185(7)$ are similar to those found in $\mathbf{1},(\mathrm{Ir}-\mathrm{Ir}$ av $=2.759(2) \AA),(\mathrm{Ir}-\mathrm{Bi}$ av = 2.734(2) А). ${ }^{7}$

Initial catalytic studies have revealed that two novel iridium-bismuth catalysts (derived from the $\mathrm{Ir}_{3} \mathrm{Bi}$ and $\mathrm{Ir}_{5} \mathrm{Bi}_{3}$ cluster complexes, see details below) are indeed active for the direct oxidation of 3-picoline to niacin (Figure 1). ${ }^{2}$ Niacin is a key component of the NADH/NAD ${ }^{+}$system that is known play an key role in many processes related to human metabolism. ${ }^{23}$ Also known as vitamin $\mathrm{B}_{3}$, niacin is an essential food element; deficiencies can lead to the disorder known as Pellagra. ${ }^{23} \mathrm{Nia}-$ cin is also known to exhibit benefits for treatments of cholesterol-related problems. ${ }^{24}$ Therefore the synthesis of niacin is of great interest, as evidenced by the range of industrial processes employed to produce it, by direct oxidation as well as via its precursor, nicotinamide, that is generated by ammoxidation of 3-picoline followed by hydrolysis - see Scheme 3, of reference $2,{ }^{25-27}$ Industrially viable routes for niacin production are well-established with solid, metal-oxide catalysts yielding over $87 \mathrm{~mol} \%$ at $300{ }^{\circ} \mathrm{C},{ }^{26}$ and microbial biocatalysts (Rhodococcus rhodochrous) producing nictonamide in a continuous fashion, albeit in a multi-step fashion. ${ }^{27}$ Whilst our previous work with the $\mathrm{Re}-\mathrm{Bi}$ catalysts achieve $\mathrm{C}-\mathrm{H}$ activation of 3picoline via ammoxidation to achieve low yields $(<5 \mathrm{~mol} \%)$ of niacin using an excess of sacrificial $\mathrm{NH}_{3}{ }^{2}$, we have adopted a more direct oxidative approach, as a proof-of-concept study, with these novel IrBi catalysts for the single-step oxidation of 3-picoline to niacin.<smiles>Cc1cccnc1[18O][Ba]</smiles>

\section{APB $=$ Acetylperoxyborate}

Figure 1. The oxidation of 3-picoline to niacin using APB.

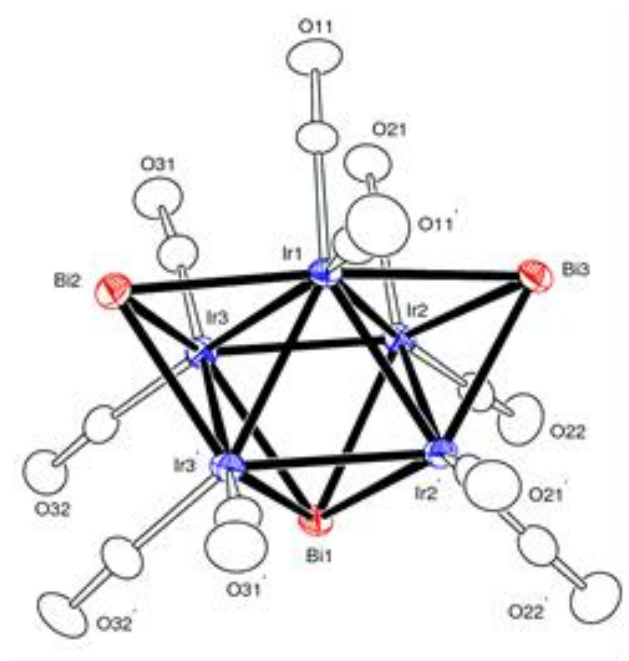

Figure 2. An ORTEP diagram of the molecular structure of $\operatorname{Ir}_{5}(\mathrm{CO})_{10}\left(\mu_{3}-\mathrm{Bi}\right)_{2}\left(\mu_{4}-\mathrm{Bi}\right), 2$ showing $30 \%$ thermal ellipsoid probability. Selected interatomic bond distances $(\AA)$ and angles $\left(^{\circ}\right)$ are as follows: $\operatorname{Ir}(1)-\operatorname{Ir}(2)=2.7824(7), \operatorname{Ir}(1)-\operatorname{Ir}(3)=$ $2.8226(7), \operatorname{Ir}(2)-\operatorname{Ir}(3)=2.7903(7), \operatorname{Ir}(2)-\operatorname{Ir}\left(2^{\prime}\right)=2.8255(9)$, $\operatorname{Ir}(3)-\operatorname{Ir}\left(3^{\prime}\right)=2.7796(9), \operatorname{Ir}(1)-\operatorname{Bi}(3)=2.8322(9), \operatorname{Ir}(1)-$ $\operatorname{Bi}(2)=2.7623(9), \operatorname{Ir}(2)-\operatorname{Bi}(3)=2.6868(7), \operatorname{Ir}(2)-\operatorname{Bi}(1)=$ 2.8004(7), $\operatorname{Ir}(3)-\operatorname{Bi}(2)=2.7002(7), \operatorname{Ir}(3)-\operatorname{Bi}(1)=2.8185(7)$.

Compounds 1 and 2 were deposited onto mesoporous (MCM-41) silica supports by the incipient wetness method and then both were converted into bimetallic IrBi nanoparticles by thermal treatments under vacuum. They were subsequently evaluated for their ability to oxidize 3-picoline to niacin catalytically by using acetylperoxyborate (APB) as the oxidant. Representative high angle annular dark field (HAADF) high resolution transmission electron microscopy images of the $\mathrm{Ir}_{3} \mathrm{Bi}$ and $\mathrm{Ir}_{5} \mathrm{Bi}_{3}$ nanoparticles after use in catalysis are shown in Figure 3. As can be seen the particles are uniformly dispersed and are less than $2 \mathrm{~nm}$ in diameter. It can also be seen that the porous character of the support was maintained during the calcination/particle formation process. Analysis of their compositions by energy dispersive $\mathrm{X}$-ray emission spectroscopy (EDS) are consistent with the $\operatorname{Ir}_{3} \mathrm{Bi}$ and $\mathrm{Ir}_{5} \mathrm{Bi}_{3}$ compositions of the precursor complexes, see Supporting Information (Tables S2 and S3).

a

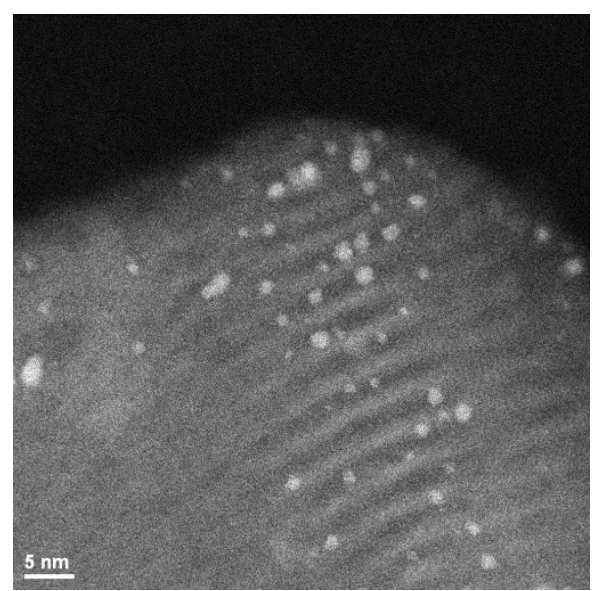




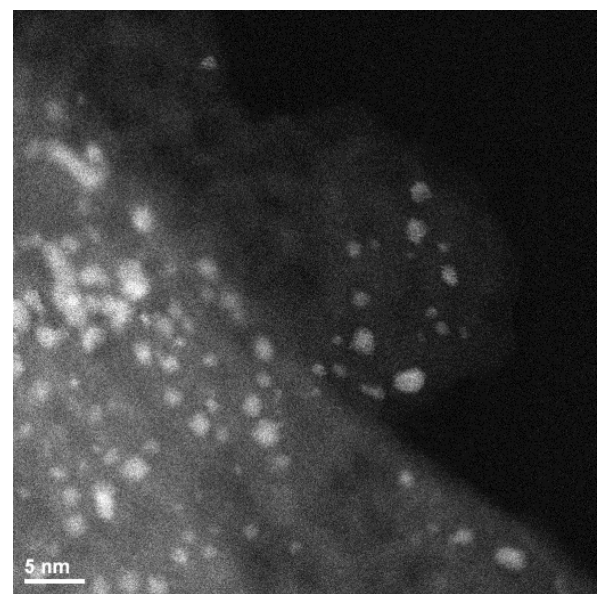

Figure 3. HAADF - HRTEM images of Ir3Bi (a) and Ir5Bi3 (b) nanoparticles on MCM-41 after use in catalysis at $65 \mathrm{oC}$. The catalysts were preconditioned/activated at $300{ }^{\circ} \mathrm{C}$ for $2 \mathrm{~h}$ before use.

The $\mathrm{Ir}_{3} \mathrm{Bi}$ nanoparticles obtained from $\mathbf{1}$ were tested for the direct oxidation of 3-picoline to niacin by using the oxidant APB. APB has been shown to be a useful reagent for selective oxidation reactions under mild conditions, serving as a solid source of active oxygen by liberating peroxyacetic acid (PAA) in situ when dissolved in water. ${ }^{28}$ For comparisons, supported forms of pure $\mathrm{Ir}$ and pure $\mathrm{Bi}, 3 \mathrm{Ir} / 1 \mathrm{Bi}$ (created from a solution of a mixture of $\operatorname{Ir}_{4}(\mathrm{CO})_{12}$ and $\mathrm{BiPh}_{3}$ combined in the appropriate ratio), $\mathrm{Ir}_{5} \mathrm{Bi}_{3}$ nanoparticles obtained from compound 2 and $5 \mathrm{Ir} / 3 \mathrm{Bi}$ particles (created from a solution of a mixture of $\mathrm{Ir}_{4}(\mathrm{CO})_{12}$ and $\mathrm{BiPh}_{3}$ combined in the appropriate ratio) were also tested. The best catalytic results were obtained by preheating the nanoparticles to $300{ }^{\circ} \mathrm{C}$ for $2 \mathrm{~h}$ under vacuum before use. The catalytic tests were performed at $65{ }^{\circ} \mathrm{C}$ for a period of $45 \mathrm{~min}$. The results of the various tests are shown in the chart in Figure 4 where blue represents the conversion of 3-picoline, red represents the selectivity of the conversion to niacin and purple represents the turnover number (TON) for niacin formation. (See also Figures S3-S6 for further catalytic details on nature of support, the effect of calcination temperature on the reactivity and selectivity along with catalyst recycle studies).

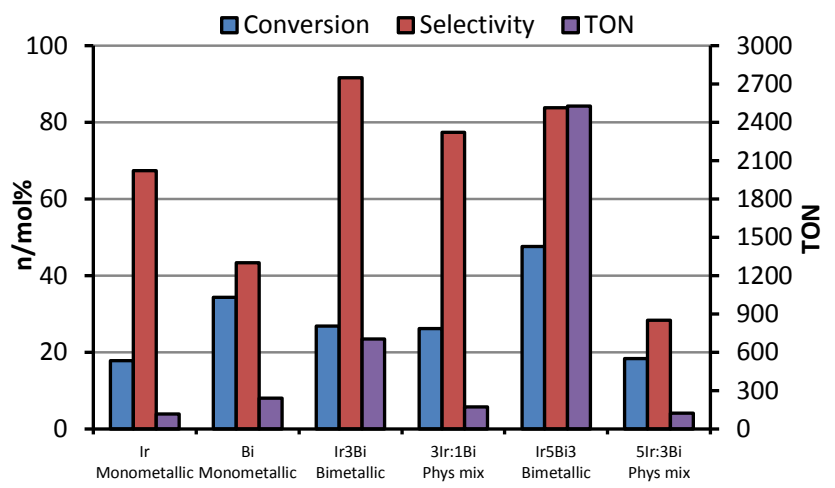

Figure 4. Comparisons of catalytic behavior of the monometallic and bimetallic Ir and Bi catalysts on MCM-41. The experiments with the physical mixtures further highlight the merits of the bimetallic cluster-based analogues. Reaction conditions: $15 \mathrm{mmol}$ of 3-picoline, 3:1 molar ratio of pico- line:peroxyacetic acid (yielded from APB), $25 \mathrm{ml}$ of $\mathrm{H}_{2} \mathrm{O}, 150$ $\mathrm{mg}$ of catalyst, $3.5 \mathrm{mmol}$ of monoglyme internal standard, 65 ${ }^{\circ} \mathrm{C}, 45$ minutes.

Pure Ir and pure Bi are ineffective catalysts as represented by the very low TONs for Niacin. The principal side product is 3-picoline-N-oxide, $\mathbf{3}$, which is the major product of oxidation with pure Bi on the support. The contrasting catalytic behaviors and catalytic opportunities afforded through the utilization of bimetallic nanoclusters are outlined in Figure 5. The monometallic Ir and Bi catalysts display distinctly different catalytic profiles (see also Figures S7-10 for kinetic profiles); while Ir clearly shows an increased selectivity for niacin, it is far less active than its Bi counterpart, which has a greater propensity for the formation of picoline $\mathrm{N}$-oxide. This difference in activity suggests that the monometallic Ir catalysts facilitate a targeted reaction pathway necessary to form niacin from picoline; whereas the monometallic Bi catalysts is far more proficient in activating the oxidant, which evokes a more diverse range of oxidation products.

The bimetallic catalysts derived from $\mathbf{1}$ and $\mathbf{2}$ are superior to the bimetallics derived by co-impregnation (the physical mix) and they exhibit the best selectivity and TONs for niacin.
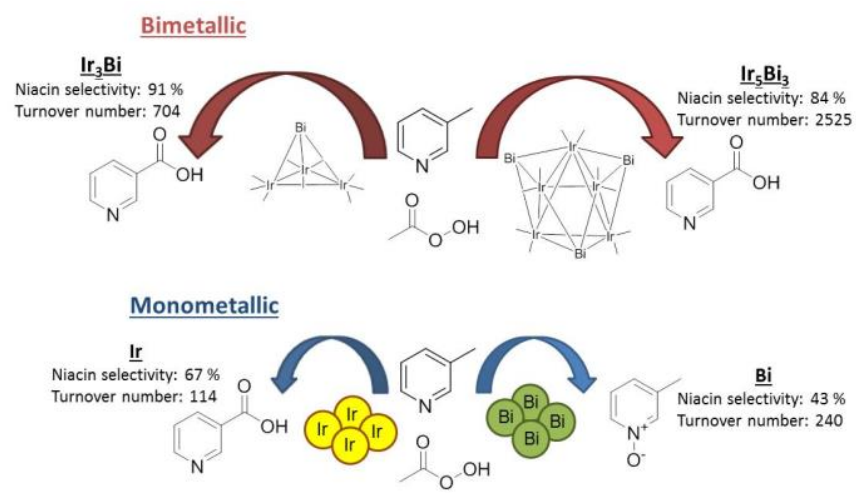

Figure 5. A schematic representation of the contrasting catalytic behaviors afforded by the Ir/Bi containing catalysts.

The attributes of the two individual metal centers are maximized by combining them to generate intimately mixed bimetallic IrBi nanoclusters, which display vastly enhanced selectivity towards the desired niacin along with a concomitant increase in catalytic efficiency (TON). The differing behavior of the $3 \mathrm{Ir}: 1 \mathrm{Bi}$ and $\mathrm{Ir}_{3} \mathrm{Bi}$ catalysts (the former being a physical mixture (prepared using identical moles of monometallic Ir and $\mathrm{Bi}$ ) strongly suggests that a specific structural integrity of the cluster is fundamental in optimizing the overall selectivity and efficiency of the catalysts in the oxidation reaction. Through careful synthetic design of the bimetallic precursor, one can ensure that the Ir and Bi metals are in close proximity to one another; a feature that cannot be readily controlled or guaranteed with the preparation of the bimetallic physical mixture. By using a cluster-based precursor, where the structural and compositional integrity can be controlled at the molecular level, it is possible to exploit the individual benefits of the two metals to facilitate a synergistic enhancement in overall catalytic behavior resulting in significant improvements in catalytic turnover. Thus, the $\mathrm{Bi}$ atoms are able to readily activate the oxidant, while the adjacent Ir atoms selectively form the niacin 
via $\mathrm{CH}$ activation processes upon the 3-picoline, ultimately creating an effective spill-over catalyst.

The catalyst derived from $\operatorname{Ir}_{5} \mathrm{Bi}_{3}$ cluster exhibited the best activity both for conversion and for catalytic efficiency (TON). This may be attributed to the $\mathrm{Ir} / \mathrm{Bi}$ ratio becoming closer to unity, thereby promoting a more efficient transfer of activated intermediates between the two metal sites. As with the $\mathrm{Ir}_{3} \mathrm{Bi}$, the cluster derived $\mathrm{Ir}_{5} \mathrm{Bi}_{3}$ catalyst was far superior to the analogous physical mixture catalyst (5Ir:3Bi), further highlighting the importance of the structural and compositional integrity provided by the cluster precursor.

In summary, the first iridium-bismuth cluster complex $\mathbf{2}$ has been synthesized and structurally characterized. The first examples of bimetallic IrBi nanoparticles have been synthesized from the bimetallic IrBi molecular cluster complexes $\mathbf{1}$ and $\mathbf{2}$. In a proof-of-concept study, these bimetallic nanoparticles exhibit superior catalytic activity for the direct oxidation 3picoline to niacin, compared to their monometallic analogues. By using cluster-based bimetallic precursors, where the compositional integrity can be better controlled at the molecular level, it is possible to produce superior nano-catalysts in order to better exploit the benefits of the individual metals by synergistic complementarity in the overall catalytic behavior. It is believed that these new iridium-bismuth catalysts will exhibit superior catalytic activity for other types of hydrocarbon oxidation reactions and will pave the way to an emerging family of precious metal-heavy main group metal bimetallic catalysts. $2,16,29$

\section{Acknowledgement}

This research was supported by the National Science Foundation CHE-1111496 (RDA). R. Raja wishes to thank EPSRC (UK) and Honeywell International (USA) for financial support.

\section{ASSOCIATED CONTENT}

Supporting Information. Supporting information includes experimental details on catalyst synthesis, crystallographic data collection and analysis, TEM (before and after catalysis) and catalysis protocols. Also included is EDS analysis, and associated catalytic and kinetic results. This information is available free of charge via the Internet at http://pubs.acs.org.

\section{AUTHOR INFORMATION}

\section{Corresponding Author}

Richard D. Adams: Adamsrd@mailbox.sc.edu, Robert Raja: R.Raja@soton.ac.uk

\section{Author Contributions}

All authors have given approval to the final version of the manuscript.

\section{REFERENCES}

(1) Hermans, S.; Raja, R.; Thomas, J. M.; Johnson, B. F. G.; Sankar, G.; Gleeson, D. Angew. Chem. Int. Ed. 2001, 40, 1211-1215.

(2) Adams, R. D.; Blom, D. A.; Captain, B.; Raja, R.; Thomas, J. M.; Trufan, E. Langmuir 2008, 24, 9223-9226.

(3) Adams, R. D.; Boswell, E. M.; Captain, B.; Hungria, A. B.; Midgley, P. A.; Raja, R.; Thomas, J. M. Angew. Chem. Int. Ed. 2007, $46,8182-8185$.
(4) Hungria, A. B.; Raja, R.; Adams, R. D.; Captain, B.; Thomas, J. M.; Midgley, P. A.; Golovko, V.; Johnson, B. F. G. Angew. Chem. Int. Ed. 2006, 45, 4782-4785.

(5) Thomas, J. M.; Adams, R. D.; Boswell, E. M.; Captain, B.; Grönbeck, H.; Raja, R. Faraday Discuss. 2008, 138, 301-315.

(6) Gianotti, E.; Shetti, V. N.; Manzoli, M.; Blaine, J. A. L.; Pearl Jr., W. C.; Adams, R. D.; Coluccia, S.; Raja, R. Chem. Eur. J. 2010, $16,8202-8209$.

(7) a. Humphrey, S. M.; Grass, M. E.; Habas, S. E.; Niesz, K.; Somorjai, G. A.; Tilley, T. D. Nano Lett. 2007, 7, 785-790. b. Vicente, B. C.; Nelson, R. C.; Singh, J.; Scott, S. L.; van Bokhoven, J. A. Catal. Today 2011, 160, 137-143. c. Bal, R.; Tada, M.; Sasaki, T.; Iwasawa, Y. Angew. Chem. Int. Ed. 2006, 45, 448-452.

(8) a. Ide, M. S.; Hao, B.; Neurock, M.; Davis, R. J. ACS. Catal. 2012, 2, 671-683. b. Lobo-Lapidus, R. J.; McCall, M. J.; Lanuza, M.; Tonnesen, S.; Bare, S. R.; Gates, B. C. J. Phys. Chem. C 2008, 112, 3383-3391. c. Boucher, M. B.; Zugic, B.; Cladaras, G.; Kammert, J.; Marcinkowski, M.; Latwon, T. J.; Sykes, E. C. H.; FlytzaniStephanopoulos, M. Phys. Chem. Chem. Phys. 2013, 15, 1218712196.

(9) Herzing, A. A.; Kiely, C. J.; Carley, A. F.; Landon, P.; Hutchings, G. J. Science 2008, 321, 1331-1335.

(10) Ishia, T.; Kinoshita, N.; Okatsu, H.; Akita, T.; Takei, T.; Haruta, M. Angew. Chem. Int. Ed. 2008, 47, 9265-9268.

(11) Corma, A.; Serna, P. Science 2006, 313, 332-334.

(12) Kesavan, L.; Tiruvalam, R.; Ab Rahim, M. H.; bin Saiman, M. I.; Enache, D. I.; Jenkins, R. L.; Dimitratos, N.; Lopez-Sanchez, J. A.; Taylor, S. H.; Knight, D. W.; Kiely, C. J.; Hutchings, G. J. Science 2011, 331, 195-199.

(13) Hinde, C. S.; Van Aswegen, S.; Collins, G.; Holmes, J. D.; Hor, T. S.; Raja, R. Dalton Trans. 2013, 42, 12600-12605.

(14) Manzoli, M.; Shetti, V. N.; Blaine, J. A. L.; Zhu, L.; Isrow, D.; Yempally, V.; Captain, B.; Coluccia, S.; Raja, R.; Gianotti, E. Dalton Trans. 2012, 41, 982-989.

(15) a. Dumitriu, D.; Bârjega, R.; Frunza, L.; Macovei, D.; Hu, T.; Xie, Y.; Pârvulescu, V. I.; Kaliaguine, S. J. Catal. 2003, 219, 337351. b. Zhao, J.; Qian, G.; Li, F.; Zhu, J.; Ji, S.; Li, L. Chin. J. Catal. 2012, 33, 771-776. c. Qian, G.; Ji, D.; Lu, G.; Zhao, R.; Qi, Y.; Suo, J. J. Catal. 2005, 232, 378-385.

(16) Hanna, T. A. Coord. Chem. Rev. 2004, 248, 429-440.

(17) Rass, H. A.; Essayem, N.; Besson, M. Green Chem. 2013, 15, 2240-2251.

(18) Wenkin, M.; Ruiz, P.; Delmon, B.; Devillers, M. J. Mol. Catal. A: Chem. 2002, 180, 141-159.

(19) He, Y.; Wu, Y.; Yi, X.; Weng, W.; Wan, H. J. Mol. Catal. A:Chem. 2010, 331, 1-6.

(20) Kruppa, W.; Blaeser, D.; Boese, R.; Schmid, G. Organische Chem. 1982, 37B(2), 209-213.

(21) Adams, R. D.; Chen, M.; Elpitiya, G.; Zhang, Q. Organometallics 2012, 31, 7264-7271.

(22) Crystallographic Data for $\mathbf{2}$ are as follow: Crystal System = orthorhombic, Space Group: Pnma, $a=16.3842(13) \AA, \quad b=$ 14.3198(11) $\AA, c=9.2009(7) \alpha=\beta=\gamma=90.00^{\circ}, \mathrm{V}=2158.7(3) \AA^{\circ}$, 1982 reflections, $\mathrm{R}=0.0286, \mathrm{R}_{\mathrm{w}}=0.0830, \mathrm{GOF}=0.99$. See Supporting Information for additional details.

(23) Kirkland, J. B.; Niacin, in Handbook of Vitamins, Rucker, R.; Zempleni, J.; Suttie, J. W.; McCormick, D.B. (Eds.), 4th ed., Taylor and Francis, New York, 2007, pp 191-232.

(24) a. Ali K. M.; Wonnerth, A.; Huber, K.; Wojta, J. Brit. J. Pharmacology 2012, 167, 1177-1194. b. Grundy, S.M. Am. J. Cardiol. 1992, 70, I27-I32.

(25) Chuck, R.; Appl. Catal. A: Gen. 2005, 280, 75-82.

(26) Petzoldt, J.; Wilmer, H.; Rosowski F. WO Patent, WO2005/118

(27) Shaw, N. M.; Robins, K. T.; Kiener, A. Adv. Synth. Catal. 2003, 345, 425-435.

(28) a. Raja, R.; Thomas, J. M.; Greenhill-Hooper, M.; Doukova, V. Chem. Commun. 2007, 1924-1926. b. Vishnuvarthan, M.; Paterson, A. J.; Raja, R.; Piovani, A.; Bonino, F.; Gianotti, E.; Berlier, G. Micropor. Mesopor. Mat. 2011, 138, 167-175. c. Raja, R.; Thomas, J. 
M.; Xu, M.; Harris, K. D. M.; Greenhill-Hooper, M.; Quill, K. Chem. Commun., 2006, 448-450.

(29) a. Mallat, T.; Bodnar, Z.; Hug, P.; Baiker, A. J. Catal. 1995, 153, 131-143. b. Brandner, A.; Lehnert, K.; Bienholz, L. M.; Claus, P. Top. Catal. 2009, 52, 278 - 287. c. Jang, J. H.; Goddard III, W. A. Top. Catal. 2001, 15, 273 - 289. d. Jang, J. H.; Goddard III, W. A. J. Phys. Chem. B 2002, 106, 5997-6013. e. Pudar, S; Oxgaard, J.;
Chenoweth, K.; van Duin, A. C. T.; Goddard III, W. A. J. Phys. Chem. C 2007, 111, 16405-16415. 


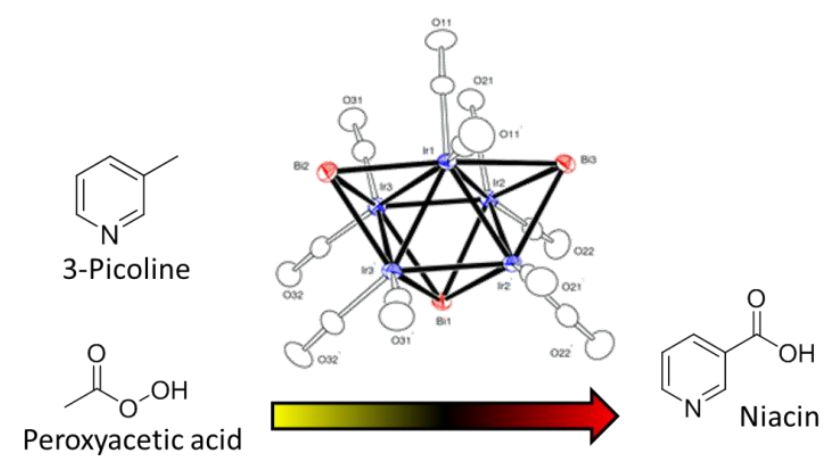

